$\overline{\text { Note }}$

\title{
Thermal Inactivation Patterns of Aspergillus niger Spores in Capillaries
}

\author{
HIROSHI FUJIKAWA ${ }^{1}{ }^{*}$, SATOSHI MOROZUMI ${ }^{1}$, GLEN H. SMEGARE ${ }^{2}$ \\ AND ARTHUR A. TEIXEIRA ${ }^{2}$ \\ 'Department of Microbiology, Tokyo Metropolitan Research Laboratory of Public Health, \\ 3-24-1 Hyakunin-cho, Shinjuku, Tokyo 169-0073, Japan \\ ${ }^{2}$ Department of Agricultural and Biological Engineering, \\ University of Florida, Gainesville, Florida, U.S.A.
}

Received 29 March 2000/Accepted 26 May 2000

\begin{abstract}
Thermal inactivation patterns of spores of a mesophilic mold, Aspergillus niger, in capillaries heated at $66-55^{\circ} \mathrm{C}$ were studied. Thermal inactivation curves of $\boldsymbol{A}$. niger spores in capillaries consisted of a shoulder and a linear decline at $66-57^{\circ} \mathrm{C}$, whereas curves at 56 and $55^{\circ} \mathrm{C}$ consisted of a shoulder, a linear decline, and a sloping tail. The Arrhenius plot of the inactivation rate for the linear decline portions in inactivation curves was a broken line at around $57^{\circ} \mathrm{C}$. The logarithm of the duration of the shoulder to the temperature was linear.
\end{abstract}

Key words: Thermal inactivation kinetics/Mold spores/Capillary procedure/Tailing.

Molds are contaminants of foods and other products, similar to bacteria (Samson et al., 1995). It is generally supposed that bacterial cells as well as mold spores are thermally inactivated following the first order kinetics (Bailey and Ollis, 1986; Shibasaki 1998; Stumbo, 1973). The thermal inactivation patterns of spores of mesophilic molds have not been intensively studied, compared with those of spores of thermoresistant molds such as Byssochlamys fulva and Neosartorya fischeri (Bayne and Michener, 1979; Engel and Teuber, 1991; King et al., 1979; Rajashekhara et al., 1996). Recently we reported that the thermal inactivation curve of spore suspensions of a mesophile, Aspergillus niger, in test tubes at constant temperatures consisted of a shoulder, a fast linear decline, and a horizontal tail at around $60^{\circ} \mathrm{C}$ (Fujikawa and Itoh, 1996 and 1998). Here test tubes containing spore suspensions stood vertically with their tops above the surface of a heating medium (circulating water) in a bath. More recently, however, we found that horizontal tail results from those test tubes

*Corresponding author. Tel: +81-3-3363-3231, Fax : +813-3368-4060 were invalid; tail cells were $A$. niger spores contaminating the inner walls of test tubes above the level of the spore suspension during the procedures (Fujikawa et al., 2000). Further we concluded that the reason for survival of inner wall contaminants was that they were not subjected to a sufficient inactivation temperature (Fujikawa et al., 2000). Consequently, we thought that a submerged capillary procedure is suitable for analysis of the inactivation kinetics of microbial cells. This is because of the absence of invalid horizontal tails from inner wall contamination of vessels, temperature homogeneity in cell suspensions, and instant rise to target temperatures, i. e., a very short "come-up time" (2 s). However, the thermal inactivation patterns of mesophilic mold spores in capillaries have been little studied. In the present study, therefore, we studied these patterns of mold spores at various temperatures.

Spores of $A$. niger ATCC 200930 were cultured on potato dextrose agar (PDA) plates as described in our previous study (Fujikawa and Itoh, 1996). Then a spore suspension was prepared with $0.1 \mathrm{M}$ dibasic sodium phosphate adjusted with $0.05 \mathrm{M}$ citric acid monohydrate to $\mathrm{pH} 7.0$ with $0.005 \%(\mathrm{~V} / \mathrm{v})$ Tween 80 
at a concentration of $2 \times 10^{8} \mathrm{spore} / \mathrm{ml}$ (Fujikawa et al., 1996). $91 \mu$ I portions of the spore suspension were put into glass capillaries $(1 \mathrm{~mm}$ in inner diameter, $120 \mathrm{~mm}$ long, Filgenberg, Malsfeld, Germany) with a syringe and then capillaries were flame sealed. Capillaries were submerged in a circulating water bath unit (DH-12, Taitec Corporation, Koshigaya, Japan) at constant temperatures between 66 and $55^{\circ} \mathrm{C}$. Subsequently, capillaries were removed at various time intervals and cooled in ice water. Outer surfaces of the capillaries were sterilized by submergence in ethanol for $10 \mathrm{~min}$. After removal of residual ethanol with sterile water, each capillary was crushed into small pieces with a glass rod in a plastic tube containing $9 \mathrm{ml}$ of saline $(0.85 \%, \mathrm{w} / \mathrm{v}, \mathrm{NaCl}$ solution). The resultant cell suspension was fully vortexed and sampled. Concentrations of survivors in the samples were enumerated by the dilution method with PDA plates (Anonymous, 1993). Data points of experiments were the averages of a set of two samples.

The total heating interval, $t$, at a constant temperature consisted of come-up time, $t_{\mathrm{c}}$, and temperatureholding period, $t_{\mathrm{h}}$; thus $t=t_{\mathrm{c}}+t_{\mathrm{h}}$. Temperature of a spore suspension in a capillary was monitored during the heating with a digital thermometer (AM-7002, Anritsu Co., Tokyo) to estimate $t_{\mathrm{c}}$. To compensate for the decrease in survivors during the come-up time, the experimental data was analyzed in terms of the survivor ratio during the heating period immediately after the come-up time, that is, $N_{\mathrm{h}} / N_{\mathrm{c}}$ during $t_{\mathrm{h}}$ (Fujikawa and Itoh, 1996). Here, $N_{\mathrm{h}}$ and $N_{\mathrm{c}}$ are the numbers of survivors heated for $t_{\mathrm{h}}$ and $t_{\mathrm{c}}$, respectively. Thermal inactivation curves were described with the survivor ratio of $N_{\mathrm{h}} / N_{\mathrm{c}}$ during $t_{\mathrm{h}}$.

A fast linear decline in an inactivation curve was analyzed for its slope, $k$, and delay, $t_{\mathrm{d}}$. The value of $k$, i.e., rate constant of the linear decline, was obtained by a linear regression of the sloping segment. The duration of a shoulder, $t_{\mathrm{d}}$, was calculated at the intersection of the regression line with the horizontal axis in the graph.

An inactivation curve with a sloping tail was analyzed with a thermotolerant subpopulation (TTSP) model, which is described below (Fujikawa and Itoh, 1996).

$$
N_{\mathrm{h}} / N_{\mathrm{c}}=p \exp \left(-k_{1} t_{\mathrm{h}}\right)+(1-p) \exp \left(\left(-k_{2}\left(t_{\mathrm{h}}-t_{\mathrm{d}}\right)\right)\right.
$$

In this model we postulated that during heating a thermotolerant and thermosensitive subpopulation of a total population would thermally be inactivated following the first order kinetics with rate constants $k_{1}$ and $k_{2}$. Here, $k_{1}<k_{2}$. Initial ratios of the thermotolerant and thermosensitive subpopulation would be $p$ and $1-$ $p$, respectively. Here, $0<p<1$. The shoulder of the inactivation curve was treated as a time delay, $t_{\mathrm{d}}$, of the
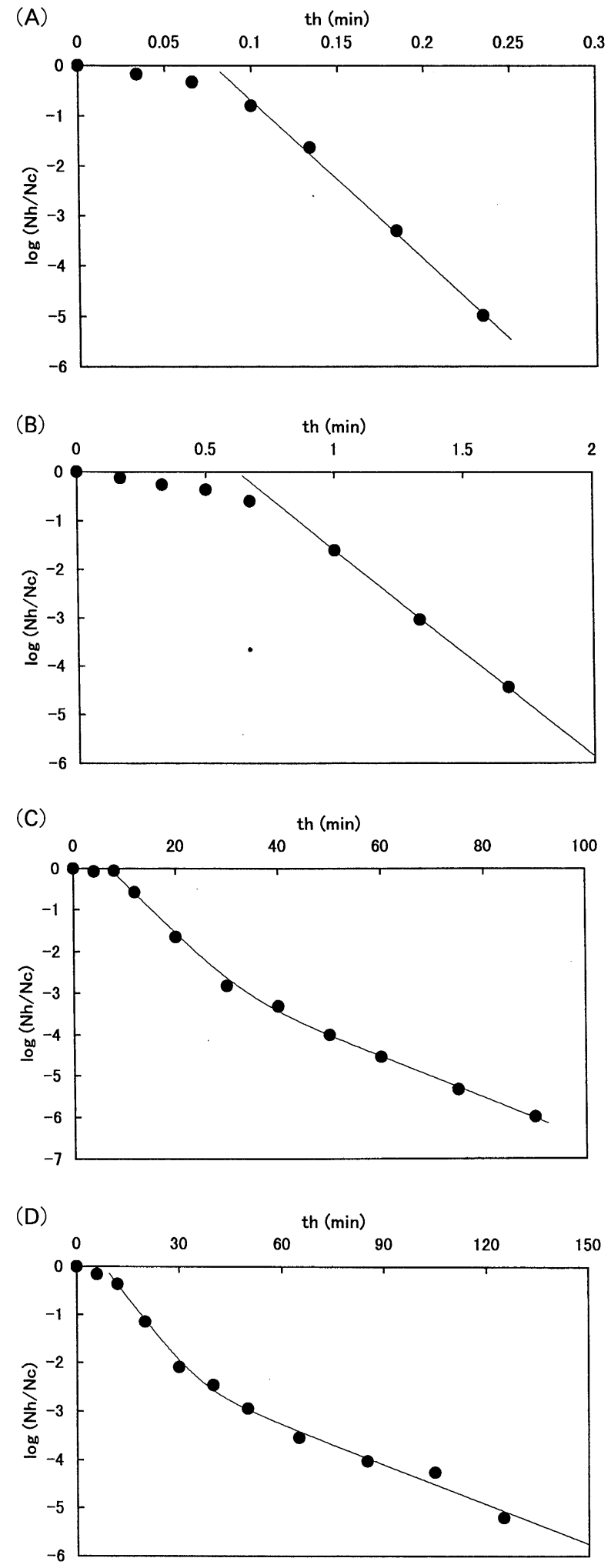

FIG. 1 . Thermal inactivation curves of $A$. niger spores in capillaries at various temperatures of $66^{\circ} \mathrm{C}(\mathrm{A}), 62^{\circ} \mathrm{C}$ (B), $56^{\circ} \mathrm{C}(\mathrm{C})$, and $55^{\circ} \mathrm{C}(\mathrm{D})$. Straight lines in $\mathrm{A}$ and $\mathrm{B}$ are regression lines for the fast linear portions of inactivation curves. Curves in C and D are fitted with a TTSP model. 
thermosensitive population inactivation.

Thermal inactivation curves of $A$. niger spores in the capillaries were studied at various constant temperatures of $66-55^{\circ} \mathrm{C} . t_{\mathrm{c}}$ at this temperature range was all $2 \mathrm{~s}$. At high temperatures of $66-57^{\circ} \mathrm{C}$, the curves consisted of a shoulder and a linear decline (Fig. $1 \mathrm{~A}$ and B). Interestingly, at temperatures lower than $57^{\circ} \mathrm{C}$, a sloping tail was observed in the thermal inactivation curve (Fig. 1C and D). The slopes were temperature dependent. The curves with sloping tails were well described with the TTSP model. Values of ratio, $p$, at 56 and $55^{\circ} \mathrm{C}$ were similar and 0.026 as an average.

For a bacterium (Salmonella Enteritidis), sloping tails in thermal inactivation curves are also found (Humpheson et al., 1998). Of interest, sloping tails for the bacterium were observed at temperatures higher than $51^{\circ} \mathrm{C}$, while inactivation curves at lower than that temperature were linear (Humpheson et al., 1998). This was contrary to the kinetics of the mold spores in this study. On the other hand, the existence of sloping tails in thermal inactivation curves shows that the linear model with parameters of $k$, or $D$ value would overestimate thermal inactivation processes concerned.

The Arrhenius analysis was done for the rate constants of the fast linear decline and the tail in the inactivation curves at the temperatures studied. The plotted line for the fast decline was a broken line at about $57^{\circ} \mathrm{C}$ (Fig. 2). The apparent activation energies of inactivation for the fast linear decline in the high temperature range $\left(66-57^{\circ} \mathrm{C}\right)$ and the low one $(57-55$ ${ }^{\circ} \mathrm{C}$ ) were estimated to be $5.63 \times 10^{5} \mathrm{~J} \mathrm{~mol}^{-1} \mathrm{~K}^{-1}$ and $1.33 \times 10^{5} \mathrm{~J} \mathrm{~mol}^{-1} \mathrm{~K}^{-1}$, with correlation coefficients of linearity of 0.998 and 0.983 , respectively. For the tail, the apparent activation energy of inactivation was $5.37 \times 10^{5} \mathrm{~J} \mathrm{~mol}^{-1} \mathrm{~K}^{-1}$.

For the shoulder in the inactivation curve, the dura-

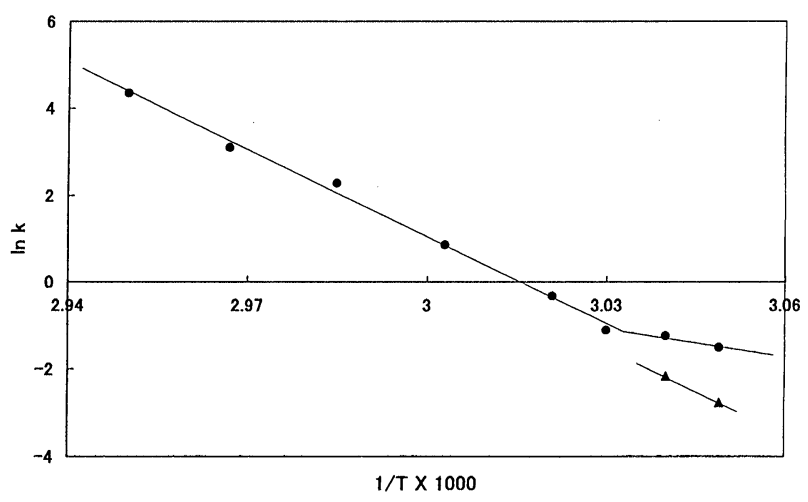

FIG. 2. Arrhenius plots for the rate coefficients of the tail $\left(k_{1}\right)$ and the fast decline $\left(k_{2}\right)$. Symbols : $\boldsymbol{\Delta}, k_{1} ; \boldsymbol{O}, k_{2}$. Lines are linear regression lines for the rate coefficients. $T$ is the absolute temperature. tion of $t_{\mathrm{d}}$ was shorter at higher temperatures (Fig. 1). A linear relationship was observed between the logarithm of $t_{\mathrm{d}}$ and the temperature (Fig. 3). The correlation coefficient of linearity was 0.975 .

Thermal inactivation curves with sloping tails at low temperatures in this study were well described with the TTSP model, a two-component model (Fig. 1). Several investigators reported that there would be two subpopulations in a single microbial population: one would be thermosensitive and the other thermoresistant (Cerf, 1977; Humpheson et al., 1998; Palop et al., 1997; Stumbo, 1973). This two-component model has also been applied to the case of non-linear inactivation kinetics of biochemical substances such as enzymes (Borhan and Snyder, 1979; Ling and Lund, 1978; Park et al., 1988). However, the reason or the mechanism for the heterogeneity of the thermal sensitivity of microbial cell and biochemical substance populations is still unknown.

Recently Humpheson et al. (1998) reported that generation of heat shock proteins in microbial cells during heating might be related to tailing, which is possibly the effect of a thermoresistant subpopulation (Allan et al., 1988; Neidhardt and Van Bogelen, 1987). It is known that heat shock proteins, which are produced by a sublethal heating, are related to the generation of the thermoresistance of treated cells. Therefore, it was thought that long come-up times, which make for long sublethal heatings, might produce enough heat shock proteins to give thermoresistance to cells, if the proteins could be made. Tsuchido et al. (1982) showed that a slow heating resulted in the thermoresistance of bacterial cells. For mold spores, however, this has not been studied to our knowledge.

We, therefore, conducted an experiment similar to that of Tsuchido et al. (1982) to study the relationship between the thermal inactivation pattern of mold

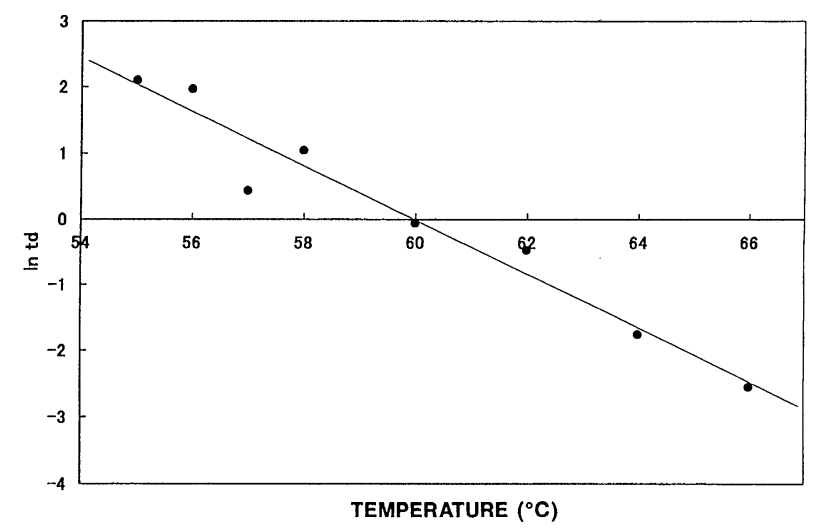

FIG. 3. Semilogarithmic plot of the time delay to the temperature. A line is a linear regression line for the delay. 


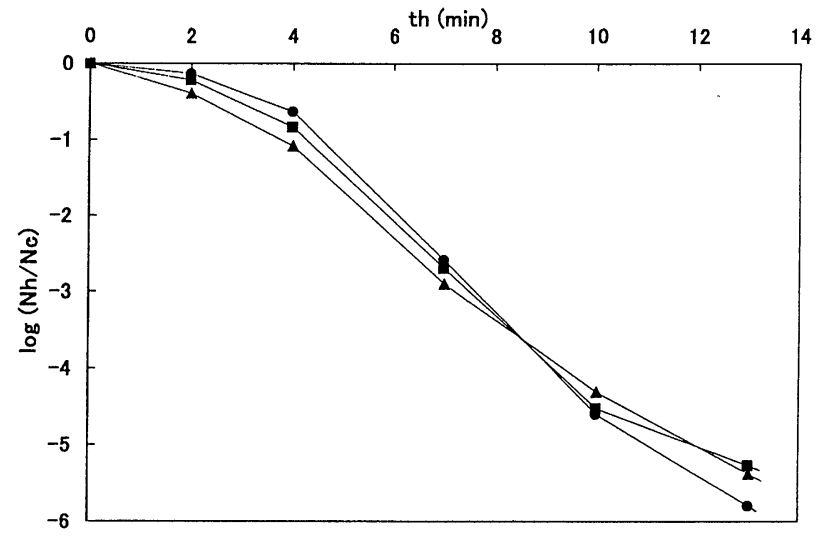

FIG. 4. Thermal inactivation curves of $A$. niger spores in capillaries at $58^{\circ} \mathrm{C}$ with various come-up times. Symbols: $\boldsymbol{A}$ $17 \mathrm{~min}$; $\mathbf{1}, 8 \mathrm{~min} ; \mathrm{O}, 2 \mathrm{~s}$.

spores and the temperature history of spores. In our experiment, $A$. niger spore suspensions in capillaries were submerged in the circulating water bath unit equilibrated at $25^{\circ} \mathrm{C}$. Then, the temperature of the circulating water was increased linearly over time to 58 ${ }^{\circ} \mathrm{C}$ and held at this temperature to obtain an inactivation curve. Different values of $t_{0}$ at $58^{\circ} \mathrm{C}$ were achieved by changing the heat output of the water bath unit and the volume of the circulating water. Temperature histories of spore suspensions were monitored with the digital thermometer (AM-7002, Anritsu). Capillaries were subsequently removed from the bath after various time intervals and cooled. Numbers of survivors in the suspensions were then enumerated. As a result, different values of $t_{\mathrm{c}}$ up to 17 min did not affect significantly the thermal inactivation patterns of $A$. niger spores, compared with controls with $t_{\mathrm{c}}$ of $2 \mathrm{~s}$, by Student's $t$-test at a level of 0.05 (Fig. 4). Further studies may be needed to clarify the relationship between sloping tail in thermal inactivation pattern and the temperature history of mold spores.

\section{REFERENCES}

Anonymous (1993) Standard Methods of Analysis in Food Safety Regulation. Japan Food Hygiene Association, Tokyo, Japan.

Allan, B., Linseman, M., MacDonald, L. A., Lam, J. S., and Kropinski, A. M. (1988) Heat shock response of Pseudomonas aeruginosa. J. Bacteriol., 170, 3668-3674.

Bailey, J. E., and Ollis, D. F. (1986) Biochemical Engineering Fundamentals, 2nd ed. MacGraw-Hill, New York.

Bayne, H. G., and Michener, H. D. (1979) Heat resistance of Byssochlamys ascospores. Appl. Environ. Microbiol., 37, 449-453.
Borhan, M. and Snyder, H. E. (1979) Lipogenase destruction in whole soybeans by combinations of heating and soaking in ethanol. J. Food Sci., 44, 586-589.

Cerf, O. (1977) A review: tailing of survival curves of bacterial spores. J. Appl. Bacteriol., 42, 1-19.

Engel, G., and Teuber, M. (1991) Heat resistance of ascospores of Byssochlamys nivea in milk and cream. Int. J. Food Micorobiol., 12, 225-234.

Fujikawa, H., and Itoh, T. (1996) Tailing of thermal inactivation curve of Aspergillus niger spores. Appl. Environ. Microbiol., 62, 3745-3749.

Fujikawa, H., and Itoh, T. (1998) Thermal inactivation patterns of Aspergillus niger spores and mycelia. Biocontrol Sci., 3, 99-103.

Fujikawa, H., Morozumi, S., Smerage, G. H., and Teixeira, A. A. (2000) Comparison of capillary and test tube procedures for analysis of thermal inactivation kinetics of mold spores. J. Food Prot., 63, 1404-1409.

Humpheson, L., Adams, M. R., Anderson, W. A., and Cole, M. B. (1998) Biphasic thermal inactivation kinetics in Salmonella enteritidis PT4. Appl. Environ. Microbiol., 64, 459-464.

King, A. D., Bayne, H. G., and Alderton, G. (1979) Nonlogarithmic death rate calculations for Byssochlamys fulva and other microorganisms. Appl. Environ. Microbiol., 37, 596-600.

Ling, A. C., and Lund, D. B. (1978) Determining kinetic parameters for thermal inactivation of heat-resistant and heat-labile isozymes from thermal destruction curves. $J$. Food Sci., 43, 1307-1310.

Neidhardt, F. C., and Van Bogelen, R. A. (1987) Heat shock response, p. 1334-1345. In Neidhardt, F. C., Ingraham, J. L., Low, K. B., Magasanik, B., Schaechter, M., and Umbarger, H. E. (ed.), Escherichia coli and Salmonella typhimurium: Cellular and Molecular Biology, vol. 2. American Society for Microbiology, Washington, D. C.

Palop, A., Sala, F. J., and Condon, S. (1997) Occurrence of a highly heat-sensitive spore subpopulation of Bacillus coagulans STCC 4522 and its conversion to a more heatstable form. Appl. Environ. Microbiol., 63, 2246-2251.

Park, K.-H., Kim, Y.-M., and Lee, C.-W. (1988) Thermal inactivation kinetics of potato tuber lipoxygenase. J. Agric. Food Chem., 36, 1012-1015.

Rajashekhara, E., Suresh, E. R., and Ethiraj, S. (1996) Influence of different heating media on thermal resistance of Neosartorya fischeri isolated from papaya fruit. J. Appl. Bacteriol., 81, 337-340.

Samson, R. A., Hoekstra, E. S., Frisvad, J. C., and Filtenborg, O. (1995) Introduction to Food-Borne Fungi. Centraalbureau voor Schimmel- cultures, Baan, The Netherlands.

Shibasaki, I. (1998) Shin-Shokuhin Sakkin Kougaku. 2nd ed. (in Japanese), Korin, Tokyo.

Stumbo, C. R. (1973) Thermobacteriology in Food Processing. Academic Press, Orlando, Florida.

Tsuchido, T., Hayashi, M., Takano, M., and Shibasaki, I. (1982) Alteration of thermal resistance of microorganisms in a non-isothermal heating process. J. Antibact. Antifung. Agents., 10, 105-109. 